\title{
MAIORES ONGS DO SETOR AMBIENTAL: UMA ANÁLISE DA DIVERSIFICAÇÃO DAS RECEITAS
}

\section{LARGEST ENVIROMENTAL NGOS: AN ANALYSIS OF REVENUE DIVERSIFICATION}

\author{
Fábio Minatto \\ Universidade Federal de Santa Catarina \\ fabio_minatto@hotmail.com \\ Ernesto Fernando Rodrigues Vicente \\ Universidade Federal de Santa Catarina \\ ernesto.vicente@ufsc.br \\ José Alonso Borba \\ Universidade Federal de Santa Catarina \\ j.alonso@ufsc.br
}

\section{RESUMO}

Objetivo: Identificar o nível de diversificação de receitas das maiores Organizações Não Governamentais (ONGs) ambientais do mundo.

Fundamento: A credibilidade é um aspecto fundamental para o setor das organizações sem fins lucrativos, pois um equívoco administrativo pode comprometer os fluxos de caixa futuros ou até mesmo decretar o fim da organização (Conway et al., 2015). Nesse sentido, a composição e o nível de diversificação das receitas dessas organizações estão relacionados com a continuidade destas.

Método: O demonstrativo contábil que evidencia as receitas auferidas das 34 ONGs do setor ambiental, relativos aos anos de 2017, 2016 e 2015, foi analisado. As ONGs estrangeiras comumente divulgam essa informação no Statement of Activities. Por meio da análise dos tipos de receita, foram elaboradas quatro categorias agregadoras, a saber: "Receita Externa", "Receita Própria", "Investimento e Juros" e "Outros". A Receita Externa, por possuir características específicas, foi subdividida em três grupos, a saber: Doação, Subvenção e Híbrido. As receitas auferidas pelas ONGs da amostra foram classificadas nas categorias elaboradas e mensurada a sua representatividade. Com o objetivo de medir o nível de diversificação, foi utilizado o indicador Hirschman-Herfindahl (HHI).

Resultados: Os principais achados evidenciaram uma ampla dependência de receitas externas, oscilando em aproximadamente $90 \%$ em relação à receita total do conjunto de organizações. A Receita Própria apresentou representatividade de aproximadamente $8 \%$ no período, enquanto a soma dos valores classificados como Investimento e Juros e Outros completa os $2 \%$ restantes. Os resultados indicam que as ONGs analisadas não apresentaram receitas diversificadas, tendo em vista que a maioria destas não apresentou indicador $H H I$ superior a 0,50. Este nível de diversificação está alinhado com aqueles sugeridos por Carroll e Stater (2009), e acima daqueles indicados por Shea e Wang (2016). 
Contribuições: Percebe-se a necessidade de classificação mais adequada das receitas, de maneira que as contas sejam dispostas de maneira mais analítica possível. Deste modo, receitas com origens distintas não estariam dispostas em conjunto. Ademais, o estudo contribui para o avanço da discussão sobre a transparência da ONGs a partir da análise de um dos seus demonstrativos.

Palavras chave: ONGs. Statement of Activities. Evidenciação. Setor Ambiental. Diversificação das Receitas.

\section{ABSTRACT}

Objective: Identify the level of revenue diversification of the world's largest non-governmental organizations (NGOs).

Background: Credibility is a crucial aspect of the non-profit sector, as an administrative misconception can jeopardize future cash flows or even decree the end of the organization (Conway et al., 2015). In this sense, the composition and level of revenue diversification of these organizations are related to their continuity.

Method: The accounting statement that shows the earned income of the $34 \mathrm{NGOs}$ in the environmental sector, related to the years 2017, 2016 and 2015, was analyzed. Foreign NGOs commonly disclose this information in the Statement of Activities. By analyzing the types of revenue, four aggregating categories were elaborated, namely: "External Income", "Own Revenue", "Investment and Interest" and "Other". The External Revenue, for having specific characteristics, was subdivided into three groups, namely: Donation, Subsidy and Hybrid. The income earned by the NGOs of the sample was classified in the categories elaborated and measured its representativeness. To measure the level of diversification, the Hirschman-Herfindahl indicator (HHI) was used.

Results: The main findings evidenced an extensive dependence on external revenues, fluctuating approximately $90 \%$ in relation to the total revenue of the group of organizations. Own Revenue represented around $8 \%$ in the period, while the sum of the amounts classified as Investment and Interest and Others completes the remaining $2 \%$. The results indicate that the NGOs analyzed did not present diversified revenues, since most of them did not present HHI indicators above 0.50. This level of diversification is in line with those suggested by Carroll and Stater (2009), and above those indicated by Shea and Wang (2016).

Contributions: There need for adequate classification of revenues is perceived, so that the accounts are arranged more reasonably. Thus, revenues with distinct would not be arranged together. Also, the study contributes to the discussion on NGO transparency based on the analysis of one statement.

Keywords: NGOs. Statement of Activities. Disclosure. Environmental Sector. Revenue Diversification.

\section{INTRODUÇÃO}

Nos últimos anos, percebe-se um aumento no interesse dos pesquisadores e gestores públicos em estudar as Organizações Não Governamentais (ONGs) (Salamon \& Sokolowski, 2016). A credibilidade é um aspecto fundamental para o setor das organizações sem fins lucrativos, pois um equívoco administrativo pode comprometer os fluxos de caixa futuros ou até mesmo decretar o fim da organização (Conway et al., 2015). Assim, a redução dos recursos, advinda da redução da confiança nessas organizações, pode fazer com que estas, inclusive as que possuem boas práticas, fechem as portas, sendo uma situação indesejável tanto para as ONGs como para os doadores (Prakash \& Gugerty, 2010). Além disso, prejudicaria a comunidade local favorecida pelos serviços prestados por estas organizações e, em sentido amplo, a sociedade. 
A confiança pode ser obtida, principalmente quando visa atrair doadores com maior poder financeiro, por meio da disponibilização de relatórios anuais e demonstrativos financeiros. Este é um dos meios para as organizações sem fins lucrativos comprovarem sua eficiência na alocação dos recursos (Conway et al., 2015; Reheul, Van Caneghem, Van den Bogaerd, \& Verbruggen, 2017). $\mathrm{Na}$ medida em que os doadores podem não conseguir observar, presencialmente, o impacto gerado pela atuação das ONGs, eles devem confiar nos relatórios financeiros como prova de competência e eficiência (Arya \& Mittendorf, 2016; Pereira, Moraes, Mattos Júnior, \& Palmisano, 2013). Portanto, percebe-se a importância de as organizações divulgarem os demonstrativos financeiros e informações relativas à sua atuação. Ao mesmo tempo, as informações não financeiras são consideradas úteis pelos doadores (Parsons, 2007) e podem influenciar a estabilidade das receitas dessas organizações (Carroll \& Stater, 2009).

Neste cenário, os doadores procuram organizações eficientes na alocação dos recursos e prestação dos serviços e estas, por sua vez, visam demonstrar essa eficiência, em seus relatórios e websites, para atrair mais doadores e, consequentemente, recursos (Arya \& Mittendorf, 2016). A imagem das ONGs deve ser positiva perante seus stakeholders, com o intuito de obter os recursos necessários para a operação (Good, Maragno, \& Borba, 2018). Nesse sentido, a divulgação de informações via websites é importante em função do seu elevado alcance e baixo custo (Bonsón-Ponte, Escobar-Rodríguez, \& Flores-Muñoz, 2006).

O relatório que evidencia a captação de receitas pelas ONGs é o Statement of Activities, demonstrativo equivalente à Demonstração do Resultado das empresas. Elas podem ser classificadas como doações, rendas auferidas e receita de investimentos (Mayer et al., 2014) ou também separando as doações em duas fontes, isto é, oriundas de empresas e do governo (von Schnurbein \& Fritz, 2017). Assim, os recursos auferidos pelas ONGs são classificados em categorias de receitas de mesma natureza, sendo isso feito de acordo com o critério estabelecido pelas organizações, tendo em vista que não existe uma regulamentação ou modelo consolidado para este fim, apesar da existência de legislação específica conforme a localização da organização.

Nesse sentido, Wilsker e Young (2010) argumentam que as entidades sem fins lucrativos auferem receitas de fontes diversas para oferecer serviços que estão em sua missão. AschariLincoln e Jäger (2015) acrescentam que características das ONGs e seu setor de atuação afetam as fontes de receitas. Assim, a composição das receitas bem como a diversificação das fontes de recursos, possivelmente, será distinta de acordo com o setor e características da organização. Ademais, para alguns recursos são impostas restrições pelos doadores (Parsons et al., 2017), sendo necessário que a ONG atinja algumas metas para que estes sejam liberados, ou seja, nem todas as receitas podem ser aplicadas a partir do momento que são auferidas.

De acordo com o The Global Journal (2018), estima-se que existem 10 milhões de ONGs ao redor do mundo. Ademais, segundo a Charities Aid Foundation (2017), que elabora o Índice Mundial das Doações, aproximadamente 30\% da população mundial doou alguma quantia financeira e $21 \%$ prestou algum tipo de serviço voluntário, em 2017. Estas informações indicam a relevância das ONGs no contexto atual, bem como a atuação de forma voluntária da sociedade.

Nessa perspectiva, destaca-se, especificamente, a relevância das ONGs que atuam no setor ambiental, dado que a preocupação com questões nessa área, como poluição, degradação dos recursos naturais e alterações climáticas, torna-se cada vez mais relevante (Mahmood, Ahmad, Ali, \& Ejaz, 2017). De acordo com Stafford, Polonsky e Hartman (2000), as ONGs que atuam no setor ambiental podem ser aliadas das empresas, disseminando alternativas mais sustentáveis do que aquelas utilizadas por estas. Essa parceria torna-se importante na medida em que as empresas estão sujeitas a pressões da sociedade, de legislações e do mercado para que operem de maneira mais sustentável (Stafford et al., 2000; Wassmer, Paquin, \& Sharma, 2014). 
Ao mesmo tempo que as ONGs podem auxiliar na redução da pressão dos agentes externos, elas podem atuar como tal, uma vez que pressionam as empresas para que elas reduzam o impacto causado no meio-ambiente (Stafford et al., 2000; Wassmer et al., 2014). Portanto, o aumento das receitas auferidas pelas ONGs que atuam neste setor pode fazer com que elas exerçam maior pressão para que as empresas se tornem mais sustentáveis e possam auxiliar nesse processo de transição, fazendo sugestões de práticas mais adequadas. Neste sentido, espera-se que com o aumento das receitas haja um aumento na pressão a ser exercida por estas. Além disso, entender quais as origens dessas receitas é relevante para compreender como estas organizações são financiadas.

Nota-se, portanto, a importância dos relatórios financeiros e da imagem das ONGs para atrair recursos e fazer com que elas possam continuar executando seus serviços. Com base no exposto, foi formulada a seguinte pergunta de pesquisa: Qual o nível de diversificação de receitas das maiores ONGs ambientais do mundo? Assim, este estudo tem como objetivo identificar o nível de diversificação de receitas das maiores ONGs ambientais do mundo.

\section{REFERENCIAL TEÓRICO}

\subsection{FAS 117 e FASB 2016-14}

ONGs, assim como empresas, possuem normas específicas de acordo com a legislação local do país no qual estão situadas. Dado que metade das organizações pertencentes à amostra final do estudo possuem sua sede principal nos Estados Unidos, e não havendo uma legislação que abranja todas as ONGs da amostra, optou-se por apresentar aspectos relevantes da legislação americana para este setor.

Nos Estados Unidos, que possuem como principal órgão normatizador de contabilidade o Financial Accounting Standard Board (FASB) que, no ano de 1993, publicou o Statement of Financial Accounting Standard no 117 (FAS 117). O FAS 117, dentre todos os documentos publicados para regular as organizações sem fins lucrativos, é considerada a principal publicação, pois, apesar das críticas, exige um modelo de divulgação amplamente aceito para reconhecimento e mensuração das atividades dessas organizações (Gordon, 2013). O principal avanço da norma foi exigir que as organizações sem fins lucrativos publicassem um conjunto de demonstrativos, a saber: Statement of Financial Position (Relatório da Posição Financeira), Statement of Activities (Relatório de Atividades), Statement of Cash Flows (Relatório dos Fluxos de Caixa) e Accompanying Notes (Notas Explicativas) (FASB, 1993).

O Statement of Activities, objeto de análise do presente estudo, deve possibilitar que o usuário da informação avalie o desempenho da organização e verifique a variação dos ativos líquidos em determinado período (FASB, 1993). Esse relatório possui semelhanças no quesito de estrutura e no que se propõe a informar com a Demonstração do Resultado, demonstrativo exigido e divulgado para as empresas em geral. Estes relatórios apresentam as receitas e despesas das organizações, sendo que a Demonstração do Resultado, no caso de empresas, informa o lucro ou prejuízo referente ao período. Para o caso de Entidades sem fins lucrativos as receitas e despesas também são apresentadas, sendo que, ao final, é informado o superávit ou déficit do exercício social.

O FAS 117 continua sendo um dos mais importantes documentos emitidos pelo FASB, especificamente para as organizações sem fins lucrativos, visto que a partir de sua publicação as organizações passaram a se preocupar com a transparência de seus dados financeiros. Desde a sua publicação, atualizações foram emitidas pelo FASB com o objetivo de incrementar os relatórios publicados pelas organizações. Essas atualizações são publicadas desde 2009 com o nome de Accounting Standards Updates (ASU) (Atualizações dos Padrões Contábeis). A seguir, no Quadro 1, 
as atualizações publicadas pelo FASB especificamente relacionadas com organizações sem fins lucrativos são elencadas.

Quadro 1 - ASUs relacionadas com as organizações sem fins lucrativos

\begin{tabular}{|c|c|c|}
\hline Data da publicação & Número & Assunto \\
\hline Janeiro/2010 & ASU 2010-07 & Fusões e aquisições \\
\hline Outubro/2012 & ASU 2012-05 & Relatório dos Fluxos de Caixa \\
\hline Abril/2013 & ASU 2013-06 & Serviços recebidos de um afiliado \\
\hline Agosto/2016 & ASU 2016-14 & Apresentação dos Relatórios Financeiros \\
\hline Janeiro/2017 & ASU 2017-02 & Consolidação \\
\hline
\end{tabular}

Fonte: Elaborado pelos autores

A atualização ASU 2016-14 influencia de maneira significativa a divulgação das organizações, visto que ela trouxe mudanças estruturais nos relatórios, principalmente o Statement of Activities. A estrutura proposta pelo FAS 117 agrupava os recursos em relação à sua restrição, em três categorias: Permanentemente Restritos, Temporariamente Restritos ou Sem Restrição. Após a entrada em vigor da ASU 2016-14, isto é, para exercícios posteriores à 15 de dezembro de 2018, são necessários somente dois grupos: Com restrição dos Doadores e Sem Restrição dos Doadores.

Recursos com restrições de doadores só podem ser aplicados pelas ONGs a partir do cumprimento de condição(ões) imposta(s) por estes. Portanto, a doação com restrição é uma maneira dos doadores controlarem seus recursos e monitorarem as organizações (Harris, Petrovits, \& Yetman, 2017; Saxton \& Guo, 2011). Então, a existência ou não de restrição nos recursos recebidos pelas organizações é um aspecto a ser considerado, tendo em vista que esta condição pode influenciar a gestão, ou seja, o não cumprimento das metas pode reduzir os recursos financeiros disponíveis.

A norma FAS 117 de 1993 e a atualização ASU 2016-14, no entanto, não mencionam um padrão quanto à nomenclatura das receitas ou grupos de receitas que devem ser seguidas. Portanto, fica a cargo da organização escolher a nomenclatura a ser dada às receitas auferidas, sendo que quanto mais clara for a denominação e mais informações forem fornecidas à respeito do evento, mais transparente estará sendo a organização.

\subsection{Transparência e Divulgação}

A transparência tem um valor intrínseco, isto é, possui um fim em si mesma, mas também pode ser utilizada para alcançar outros objetivos primários de uma organização, como accountability, efetividade e legitimidade (Hyndman \& McConville, 2016). A eficiência, por exemplo, só pode ser mensurada caso a organização seja transparente e divulgue em seus relatórios as informações e valores necessários para calcular os indicadores.

Nesse sentido, as organizações devem divulgar informações requisitadas pelas legislações e regulamentos a que estão sujeitas, mas também podem divulgar além do mínimo exigido. Esse procedimento é válido para atrair doadores, no caso de ONGs, visando demonstrar fidedignidade e atestar que o trabalho é de alta qualidade, convencendo um público cada vez mais cético (Becker, 2018) e aumentando o fluxo de recursos para este setor (Keating \& Frumkin, 2003). Esse processo já foi iniciado nas organizações sem fins lucrativos, visto que há organizações aumentando o nível de transparência recentemente (Becker, 2018).

O processo de comparação de organizações é afetado pelo nível de transparência das informações financeiras, sendo um fator analisado, por exemplo, pelos doadores de recursos. Portanto, há um problema quando os doadores não conseguem distinguir as organizações mais eficientes e transparentes, pois o fluxo de recursos deveria ser direcionado para as organizações mais eficientes em detrimento das demais (Prakash \& Gugerty, 2010). 
Nesse sentido, Tristão e Tristão (2016) destacam que uma prática importante para as ONGs, quando da parceria com outras organizações, está relacionada com a transparência das informações. Evidenciar adequadamente suas informações auxilia no processo de legitimidade junto à outra organização parceira, bem como para a sociedade civil, posteriormente. Ademais, a transparência na divulgação de resultados é fator essencial para a sustentabilidade da organização (Pereira et al., 2013).

A divulgação das informações referentes aos resultados da organização pode ser analisada pelo viés quantitativo, isto é, a quantidade de informações divulgadas. Simultaneamente, no entanto, é necessário olhar por um viés da qualidade da informação prestada, tendo em vista que se exige que a organização divulgue de maneira adequada essas informações (Pacheco, Macagnan, \& Seibert, 2016).

Assim, a transparência de como os recursos são obtidos, por exemplo, ajuda a reduzir a assimetria informacional existente entre doadores e os gestores da organização. Com a evidenciação de forma mais clara, a credibilidade pode ser aumentada e os doadores dos recursos que financiam essa organização podem entender melhor as decisões tomadas naquele contexto (Gálvez Rodríguez, Caba Pérez, \& López Godoy, 2012; Keating \& Frumkin, 2003).

Outro redutor de assimetria importante nesse processo é a asseguração alcançada por meio do trabalho da auditoria externa. Ressalta-se que o trabalho da auditoria externa nas ONGs pode ter diferenças consideráveis na comparação com empresas com fins lucrativos. Diferenças culturais, de estruturas organizacionais, necessidades financeiras, regras de contabilidade e relatórios financeiros, usuários das informações e o risco de auditoria nestes ambientes são exemplos dessas diferenças (Tate, 2007).

A auditoria externa, no processo de verificação dos relatórios contábeis das ONGs, colabora para a redução de falhas na evidenciação das informações (Burks, 2015). Portanto, espera-se que as ONGs que possuem auditoria das suas informações passem um nível de credibilidade maior para seus usuários, sejam eles internos (gestores), sejam externos (doadores).

\subsection{Receitas das ONGs}

As receitas das organizações sem fins lucrativos podem ser classificadas em três ou quatro grandes grupos, não havendo um consenso na literatura. As fontes de recursos, quando divididas em três grupos, são classificadas como doações, rendas auferidas e receita de investimentos (Mayer et al., 2014). A distinção feita, quando da divisão em quatro grupos, é separar as doações em recursos obtidos por meio de empresas e do governo, permanecendo com o grupos de rendas auferidas e receita de investimentos (von Schnurbein \& Fritz, 2017). Essas classificações, no entanto, dependem do grau de divulgação das organizações, visto que algumas vezes elas não fazem essa separação nas demonstrações financeiras. $O$ mais adequado, pela ótica da transparência, é que as organizações divulguem os dados de maneira pormenorizada, visando à possibilidade de analisar-se adequadamente a origem dos recursos.

As ONGs, bem como a maioria das entidades sem fins lucrativos, apresentam uma característica marcante sobre a origem de suas receitas. Ao contrário das empresas, frequentemente seus serviços ou produtos serão vendidos por um preço abaixo do mercado ou gratuitamente (von Schnurbein \& Fritz, 2017). Como consequência, elas devem estabelecer outras fontes de renda, tendo em vista que esse tipo de receita descrito não as sustentará, de modo que possam atingir seus objetivos.

O objetivo da divulgação de informações referentes à origem das receitas dessas organizações, bem como a elaboração de demonstrativos contábeis completos, é auxiliar gestores, diretores e doadores na avaliação do desempenho da organização (Burks, 2015; Reheul et al., 2017). Os usuários que possuem maior interesse nesse tipo de divulgação, usualmente, são doadores de 
grande porte, tendo em vista que para fazer a doação de grandes montantes é necessário confiar sobremaneira na gestão da organização.

De acordo com Saxton, Neely e Guo (2014) a divulgação por meio da internet pode exercer papel vital para as entidades sem fins lucrativos captarem mais recursos. Finalmente, a divulgação de relatórios anuais, segundo Conway et al. (2015), é uma forma de responder a possíveis ameaças à legitimidade da organização.

Nesse sentido, a reputação da organização eleva ou reduz o montante de recursos, financeiros e não financeiros que ela recebe (Conway et al., 2015). Essa reputação é ameaçada à medida que escândalos ocorrem (Becker, 2018) e gera uma necessidade de maior transparência (Gálvez Rodríguez et al., 2012). Assim, a legitimidade é relevante no contexto das ONGs, dado que existe uma competição pelos recursos escassos existentes e estas organizações são dependentes de receitas externas (Conway et al., 2015; Gálvez Rodríguez et al., 2012; Verbruggen, Christiaens, \& Milis, 2011).

\subsection{Pesquisas Relacionadas}

A análise das receitas das ONGs, apesar de sua relevância, ainda não é amplamente realizada nos estudos. No entanto, há na literatura trabalhos que analisaram a transparência e receitas das ONGs e de organizações sem fins lucrativos, os quais são expostos a seguir.

Saxton e Guo (2011) elaboraram um checklist visando analisar a Accountability online das organizações sem fins lucrativos. Foram analisados aspectos divulgados em relatórios anuais, demonstrativos financeiros, políticas de privacidade, entre outros relatórios, de 117 organizações. Os resultados sugerem que os websites foram mais efetivos para divulgar elementos financeiros e de desempenho do que para fornecer mecanismos de diálogo visando à participação dos usuários.

Good et al. (2018) ampliaram o checklist desenvolvido por Saxton e Guo (2011), acrescentando a divulgação financeira como aspecto a ser observado. Foram analisados os relatórios anuais e demonstrativos financeiros das ONGs participantes do ranking divulgado pelo The Global Journal "The Top 100 NGOs 2013". Por meio de análise de correspondência e homogeneidade, os resultados indicam que o nível de divulgação é associado com o tamanho da organização, isto é, que há uma relação entre tamanho e divulgação das informações.

As pesquisas acima ressaltam a importância da divulgação online das informações relacionadas com as entidades sem fins lucrativos. As ONGs, objetos do presente estudo, de acordo com a pesquisa de Good et al. (2018), podem se comunicar de maneira efetiva com seus stakeholders, por meio da divulgação de seus relatórios, sendo uma ferramenta importante de diálogo.

Mayer et al. (2014) analisaram a relação entre a diversificação das receitas e a volatilidade das organizações sem fins lucrativos. Esperava-se que, pela teoria moderna do portfólio (Markowitz, 1952), quanto maior a diversificação menor seria a volatilidade das organizações. Os resultados encontrados, no entanto, mostraram que a composição influencia o comportamento, isto é, trocando receita própria por doações reduziu-se tanto a volatilidade como o valor total das receitas. Quando da troca de doações por investimentos, a volatilidade era reduzida e o valor total das receitas arrecadadas aumentado, sendo um dos motivos para organizações manterem investimentos.

Carroll e Stater (2009) investigaram se a diversificação das receitas gera maior estabilidade em entidades sem fins lucrativos. Os resultados indicam que as entidades podem reduzir a volatilidade das receitas por meio da diversificação, sugerindo, ainda, uma relação inversa entre longevidade e volatilidade nas receitas.

Por outro lado, os estudos de Chikoto e Neely (2014) e von Schnurbein e Fritz (2017) indicam que a concentração das receitas em determinadas fontes pode ser benéfica para entidades 
sem fins lucrativos. Chikoto e Neely (2014), com dados referentes ao período de 1998-2003, testaram se a concentração de receitas é uma estratégia viável para entidades sem fins lucrativos aumentarem sua capacidade financeira. Os resultados sugerem que, implementando uma estratégia de concentração nas origens de receita, é gerado um efeito positivo na capacidade financeira e na receita total da organização.

Von Schnurbein e Fritz (2017), por meio da análise de 200 instituições de caridade suíças testaram a influência da diversificação das receitas no crescimento financeiro das entidades sem fins lucrativos. Os resultados da pesquisa indicam que, no período de 2005 a 2012, as organizações com maior concentração de receitas apresentaram maior crescimento do que as outras.

Good, Borba e Maragno (2015) analisaram as fontes de recursos e a dependência das ONGs. Os dados foram coletados em Relatórios Anuais e Demonstrativos Financeiros, referentes ao ano de 2013. As origens de recursos foram classificadas em categorias, a saber: Doações, Subvenções, Receitas, Investimento e Juros, Outros e Híbrido. A fonte de recursos mais relevante, de acordo com a pesquisa, foram as doações, e as organizações pertencentes à amostra mostraram-se altamente dependentes de apenas uma fonte de recursos.

Percebe-se, a partir da leitura dos estudos listados acima e dos seus principais achados, a importância da divulgação financeira por parte das ONGs e a necessidade de estudo da origem dos recursos dessas organizações. A partir do aumento do volume financeiro e do aumento no número de doadores e, consequentemente, de stakeholders, cresce a responsabilidade de gerir esses recursos e mostrar que a organização está aplicando-os de maneira eficiente na consecução de seus objetivos. Por isso, percebe-se a necessidade de pesquisar as receitas dessas organizações, classificando-as, de maneira que se torne possível identificar suas origens e representatividade no total da arrecadação.

\section{PROCEDIMENTOS METODOLÓGICOS}

\subsection{Seleção da Amostra}

O ranking "Top 500 NGOs World 2018" visa selecionar ONGs com as melhores práticas de inovação e governança e que causam um relevante impacto na sua zona de operação (NGOAdvisor, 2018). As organizações que participam desse ranking e pertencem ao setor ambiental compõem a população do estudo. As organizações pertencentes ao setor ambiental foram selecionadas a partir da utilização do filtro "ambiental" no website do ranking. A partir desse filtro, obteve-se como resultado 56 ONGs. Nesse sentido, caracteriza-se a seleção da amostra como não probabilística e por acessibilidade aos dados.

A partir dessa seleção, o website das organizações foi procurado com o objetivo de coletar os demonstrativos financeiros. Vinte organizações não divulgaram seus dados financeiros em um demonstrativo estruturado ou não divulgaram um relatório anual em meios eletrônicos, sendo excluídas da amostra.

O período de referência para análise dos relatórios teve como recorte os anos de 2015 a 2017, sendo que organizações que divulgaram pelo menos dois relatórios foram incluídas na amostra do estudo. Assim, 32 ONGs divulgaram os demonstrativos nos três anos e apenas duas divulgaram em dois anos. Finalmente, duas organizações divulgaram apenas um relatório no período de três anos, sendo excluídas da amostra. Portanto, 34 ONGs (61\% da população) fizeram parte da amostra final e tiveram seus demonstrativos analisados.

Faz-se necessário ressaltar, como mencionado no estudo de Good et al. (2015), que a não publicação dos relatórios em meio online não significa que esses documentos não foram elaborados pelas organizações. Elas podem ter publicado em outros meios (jornais, por exemplo) e não constar em seu website. 


\subsection{Coleta dos Dados}

Os dados referentes às receitas das ONGs foram retirados dos demonstrativos financeiros ou dos relatórios anuais disponibilizados nos websites das organizações, mais especificamente, do demonstrativo Statement of Activities ou equivalente (Statement of Income, Profit and Loss Statement). Esses demonstrativos evidenciam as receitas e despesas das organizações, sendo similares à Demonstração do Resultado do Exercício. A coleta foi realizada durante os meses de março e abril de 2018, para os anos de 2016 e 2015, e em abril de 2019 para os demonstrativos referentes ao ano de 2017.

Após a coleta das receitas divulgadas pelas organizações em seus demonstrativos, estas foram convertidas para Dólares Americanos - United States Dollar (USD) por meio do website https://www.xe.com/currencytables/ tendo como data-base o último dia do exercício social da organização que constava no relatório. Os demonstrativos das organizações pertencentes à amostra foram analisados em três idiomas, a saber: Inglês, Português e Francês. Essas informações foram tabuladas por meio do software Excel, o qual também foi utilizado para elaboração de gráficos e das estatísticas descritivas.

Além de informações sobre a composição de receitas das organizações, foram coletados o ano de fundação das ONGs, o país onde se localiza sua sede principal e a empresa que auditou seus demonstrativos. O país foi coletado por meio do website NGOAdvisor (2018), o ano de fundação nos websites das organizações e a empresa de auditoria nos demonstrativos das ONGs, especificamente do parecer de auditoria.

\subsection{Categorização das Receitas}

Para atender o objetivo do trabalho, foi elaborada uma categorização de receitas com base na análise dos demonstrativos das organizações pertencentes à amostra e nos estudos de Good et al. (2015), Mayer et al. (2014) e von Schnurbein e Fritz (2017). Foram considerados esses três estudos, bem como a análise dos relatórios das organizações pertencentes à amostra desta pesquisa, pois não há um modelo consolidado para a análise das receitas em ONGs na literatura existente. A seguir, no Quadro 2, as categorias de receitas são explicadas e exemplos são fornecidos.

\section{Quadro 2 - Categorização das Receitas}

\begin{tabular}{|c|l|}
\hline Categoria & \multicolumn{1}{c|}{ Classificação } \\
\hline Receita Própria & $\begin{array}{l}\text { Recursos obtidos por meio da execução das suas operações, por exemplo: Vendas de mercadorias, } \\
\text { Prestação de Serviços, Licenciamentos e Royalties. }\end{array}$ \\
\hline Receita Externa & $\begin{array}{l}\text { Recursos monetários e não monetários obtidos por meio de terceiros (governo, pessoas, empresas e } \\
\text { fundações) para financiar suas atividades. Essa categoria foi subdividida em três grupos, a saber: } \\
\text { Subvenções, Doações e Híbrido. As doações, subvenções e contribuições são os principais exemplos } \\
\text { dessa categoria. }\end{array}$ \\
\hline $\begin{array}{c}\text { Investimento e } \\
\text { Juros }\end{array}$ & $\begin{array}{l}\text { Recursos obtidos pela venda de ativos físicos ou pela remuneração pelo empréstimo dos mesmos, por } \\
\text { exemplo: Receita com Investimento e Juros, Receita com Aluguel, Ganho na Venda de Imobilizado. }\end{array}$ \\
\hline Outros & Recursos não detalhados ou especificados como diversos, por exemplo: Outras Receitas e Diversos. \\
\hline
\end{tabular}
Fonte: Elaborado pelos autores

A categoria Receita Externa foi subdivida em três subgrupos em função da maior diversidade de itens de receita, quando comparada com as outras três categorias do presente estudo. O subgrupo híbrido fez-se necessário devido à impossibilidade de discriminar alguns tipos de receita como Doações ou Subvenções. A organização One Acre Fund, por exemplo, divulgou um item de receita, tanto em 2016 como em 2015, nomeado Subvenções e Doações. No presente estudo este item foi considerado Híbrido, pois há características dos dois subgrupos no item mencionado, sendo inexequível separar adequadamente os valores. 


\subsection{Diversificação das Receitas}

Para investigar o nível de diversificação de receitas, optou-se pelo Hirschman-Herfindahl Index (HHI), conforme utilizado por Shea e Wang (2016), descrito na Equação 1.

$$
H H I=\left[1-\sum\left(\frac{\text { fonte de receita }}{\text { total da receita }}\right)^{2}\right.
$$

O HHI propõe que quanto mais próximo de 1 , mais diversificada é a receita de uma organização, ou seja, possui múltiplas. Ao contrário, quanto mais próximo de zero menor é a diversificação, indicando que as organizações tendem a ser dependentes de uma ou poucos tipos de receitas. Assim, quando uma entidade apresenta $\mathrm{HHI}=0$, entende-se que ela é dependente de uma única receita (Shea \& Wang, 2016).

O indicador HHI foi utilizado para medir o nível de diversificação de receitas das ONGs que compuseram a amostra.

\section{ANÁLISE DOS RESULTADOS}

São apresentados a seguir uma contextualização das ONGs pertencentes à amostra, bem como os principais resultados relacionados com as fontes de recursos utilizadas por elas.

\subsection{Contextualização das ONGs}

O ano de fundação das ONGs, o continente onde se localiza sua sede principal, e a empresa que auditou seus demonstrativos são descritos na sequência. A partir dessas informações é possível identificar características importantes da composição da amostra do presente estudo.

Por meio dos websites e relatórios anuais das ONGs foi possível encontrar o ano em que a organização foi fundada. A partir dessas informações foi elaborado o Gráfico 1, que evidencia as fundações das ONGs por década.

\section{Gráfico 1 - Fundações de ONGs por década (1940-2018)}

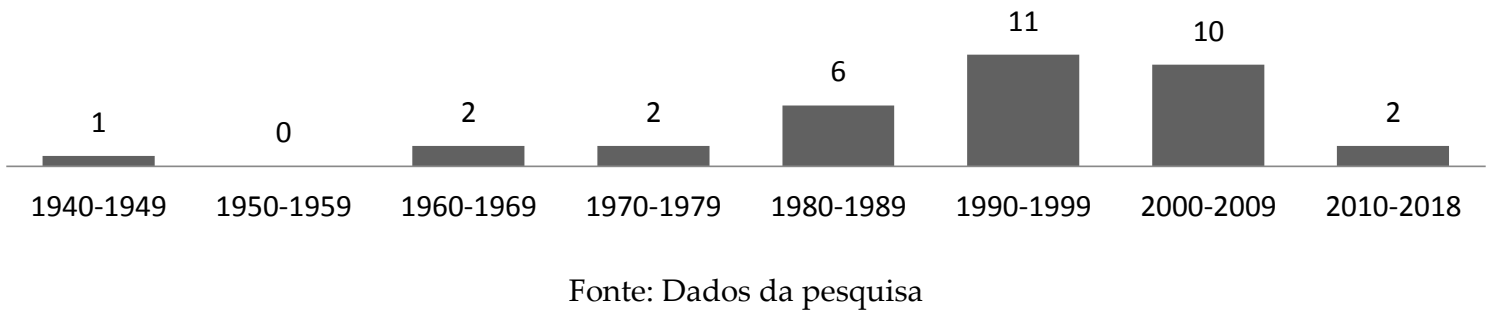

Percebe-se que o período entre 1990 e 2009 foi onde houve a maior concentração de fundações de ONGs da amostra deste estudo. De maneira mais específica, o ano de 1993 foi o mais positivo nesse sentido, com quatro ONGs fundadas. O maior envolvimento da sociedade para temas relacionados com o meio ambiente pode explicar o aumento no número de ONGs que atuam neste setor. Esse engajamento pode ter sido incutido na sociedade por alguns eventos que ocorreram anos antes, como a Convenção-Quadro das Nações Unidas sobre Mudanças Climáticas (1990) e, principalmente, a Eco-92 (1992).

Por meio da base de dados NGOAdvisor (2018), foi possível coletar o país onde a ONG possui sua sede principal. A partir dessas informações, foi elaborado o Gráfico 2. 


\section{Gráfico 2 - Número de Sedes das ONGs por continente}

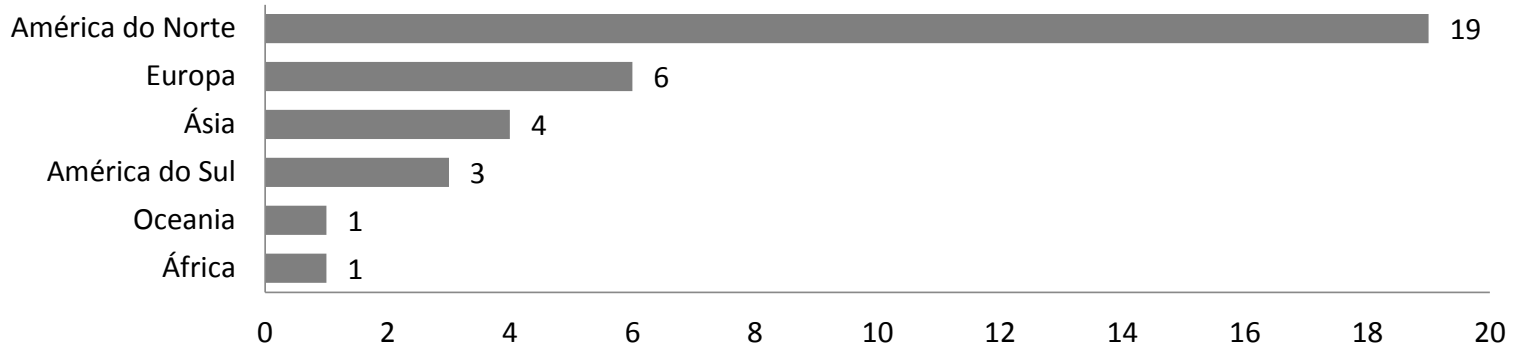

Fonte: Dados da pesquisa

Depreende-se uma concentração no continente norte-americano, mais especificamente nos Estados Unidos, onde 17 ONGs possuem sua sede principal. O país que ficou em segundo lugar foi o Brasil, com três ONGs sediadas em seu território. Os outros países em que as ONGs da amostra final possuem suas sedes principais são: Canadá, Suíça, Holanda, França, Reino Unido, Índia, China, Austrália, Líbano e Quênia.

A partir da análise do país da sede principal da organização com o valor total das receitas auferidas no ano de 2016, as três maiores ONGs, por esta métrica, são de países distintos. A organização com maior arrecadação foi a Clinton Foundation, com sede nos Estados Unidos, seguida por Viva Rio e Acted, do Brasil e França, respectivamente. Dentre as dez maiores organizações, seis estão localizadas nos Estados Unidos, sendo algo esperado pela predominância do país na amostra do estudo.

A utilização de um auditor externo no processo de verificação dos relatórios contábeis das ONGs, contribui para a redução de erros de evidenciação (Burks, 2015). Além disso, caso essa empresa pertença ao grupo das Big Four, essa contribuição é maior do que a média das outras empresas de auditoria (Vermeer, Edmonds, \& Asthana, 2014). Por conseguinte, os stakeholders valorizam essa asseguração fornecida pelas empresas de auditoria (Reheul et al., 2017).

Assim, verifica-se na Tabela 1 que as empresas de auditoria são categorizadas entre Big Four e não Big Four, sendo apresentado ainda o número das organizações auditadas e não auditadas.

Tabela 1 - Empresas de Auditoria

\begin{tabular}{c|c}
\hline Empresa de Auditoria & Organizações Auditadas \\
\hline Não Big Four & 25 \\
Big Four & 3 \\
Não auditada & 6 \\
\hline Total & 34 \\
\hline
\end{tabular}

Fonte: Elaborado pelos autores

Os demonstrativos foram auditados em 28 das 34 organizações, refletindo a importância desse procedimento. As empresas que auditaram estas organizações, em sua grande maioria, não compõem o grupo das quatro maiores empresas de auditoria do mundo, conhecidas por Big Four. As empresas Big Four que auditaram organizações da amostra foram a PWC, auditando duas organizações, e a KPMG, com uma organização auditada. Algumas empresas de auditoria Não Big Four que auditaram as organizações da amostra foram: BDO, RSM, Grant Thornton e Nexia. 


\subsection{Fontes dos Recursos}

De acordo com a classificação elaborada na seção 3.3, as receitas obtidas pelas organizações foram estruturadas em quatro categorias, a saber: Receita Externa, Receita Própria, Investimento e Juros e Outros.

O Gráfico 3 evidencia o valor arrecadado no período somando todas as receitas auferidas pelas organizações pertencentes à amostra final, conforme a classificação elaborada no presente estudo.

\section{Gráfico 3 - Valor total arrecadado por categoria de receita (2015-2017)}

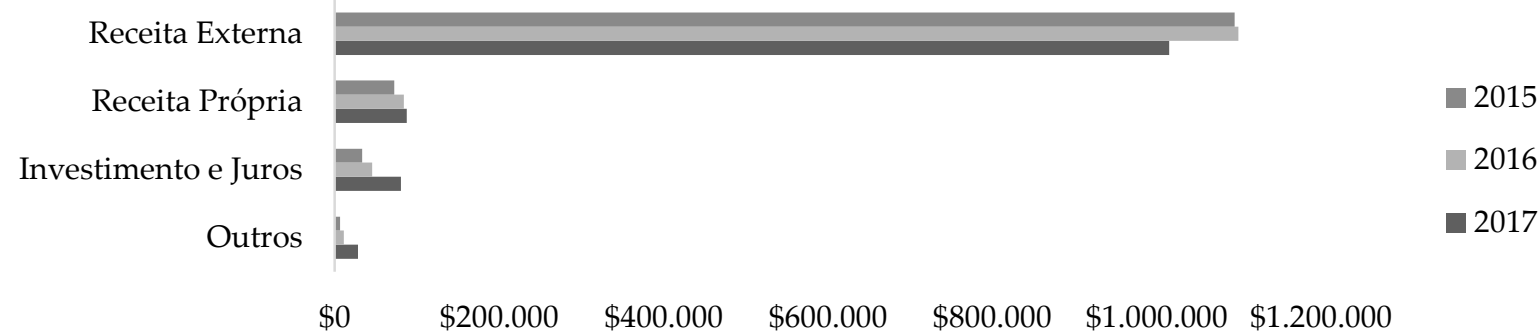

Nota. Valores em milhares de USD. Fonte: Dados da pesquisa

O Gráfico 3 evidencia a importância da categoria Receita Externa para as organizações da amostra deste estudo, pois representa aproximadamente $90 \%$ dos recursos arrecadados pelas ONGs no período. Nota-se, também, que houve um aumento no valor arrecadado em todas as categorias entre os anos de 2015 e 2016. A Receita Própria apresentou representatividade de aproximadamente $8 \%$ no período para as ONGs da amostra. O montante dos valores classificados como Investimento e Juros e Outros completa os $2 \%$ restantes.

Para o ano de 2017 houve um aumento nos valores classificados como Investimento e Juros e na categoria Outros. O aumento na categoria Outros demonstra falta de transparência por parte das organizações, tendo em vista que, à medida que o montante se torna relevante, espera-se que a ONG evidencie melhor a origem deste recurso.

$\mathrm{Na}$ Tabela 2, as estatísticas descritivas, com análise específica para as contas evidenciadas pelas organizações, das categorias Receita Externa, Receita Própria, Investimento e Juros e Outros são apresentadas.

Tabela 2 - Estatística Descritiva das Categorias de Receitas (2015-2017)

\begin{tabular}{ccrrrrrrr}
\hline Estatística Descritiva & Ano & Mínimo & \multicolumn{1}{c}{ Q1 } & Mediana & \multicolumn{1}{c}{ Q3 } & \multicolumn{1}{c}{ Máximo } & \multicolumn{1}{c}{ Média } & Desvio Padrão \\
\hline \multirow{4}{*}{ Receita Externa } & $2015(\$)$ & 20 & 122.076 & 551.316 & 3.309 .073 & 182.501 .956 & 10.532 .431 & 32.028 .397 \\
& $2016(\$)$ & 8 & 105.046 & 537.249 & 3.520 .518 & 202.214 .204 & 10.888 .220 & 33.327 .939 \\
& $2017(\$)$ & 20 & 87.352 & 798.493 & 3.228 .651 & 234.562 .452 & 6.534 .197 & 36.301 .552 \\
\hline \multirow{3}{*}{ Receita Própria } & $2015(\$)$ & 162 & 23.871 & 79.685 & 1.141 .841 & 26.641 .727 & 2.603 .506 & 6.021 .194 \\
& $2016(\$)$ & 152 & 13.955 & 162.437 & 1.760 .846 & 34.056 .114 & 3.012 .287 & 7.301 .864 \\
& $2017(\$)$ & 5 & 13.561 & 119.958 & 1.055 .116 & 45.864 .274 & 2.736 .863 & 8.318 .466 \\
\hline \multirow{3}{*}{ Investimento e Juros } & $2015(\$)$ & 26 & 621 & 24.954 & 41.432 & 4.580 .772 & 321.075 & 1.034 .742 \\
& $2016(\$)$ & 4 & 4.081 & 22.650 & 44.149 & 9.680 .612 & 663.931 & 2.082 .052 \\
& $2017(\$)$ & 9 & 2.334 & 22.392 & 104.134 & 28.463 .577 & 2.984 .792 & 8.505 .542 \\
\hline \multirow{3}{*}{ Outros } & $2015(\$)$ & 720 & 10.632 & 70.751 & 185.443 & 2.645 .941 & 319.071 & 667.671 \\
& $2016(\$)$ & 532 & 5.268 & 76.965 & 245.270 & 5.042 .060 & 528.152 & 1.287 .727 \\
& $2017(\$)$ & 92 & 10.944 & 44.467 & 623.099 & 15.930 .704 & 1.167 .141 & 3.328 .104 \\
\hline
\end{tabular}

Nota. Valores em USD. Fonte: Dados da pesquisa 
Os valores mínimos para todas as categorias foram baixos, na comparação com os valores dos primeiros quartis, pois algumas organizações apresentaram receitas realmente diminutas em suas demonstrações financeiras. Os \$ 8 apresentados como valor mínimo em 2016 para a categoria receita externa foram auferidos pela organização Goonj. A organização apresentou esse valor como referente à taxa de adesão, mas não forneceu maiores explicações, possivelmente pela representatividade do valor para ela. Além disso, esta organização apresentou suas demonstrações na moeda corrente da Índia e ela estava desvalorizada em relação ao dólar americano no momento da conversão.

Nota-se que os valores de Desvio Padrão encontrados para as categorias de receitas, principalmente para a categoria Receita Externa, demonstram variabilidade dos dados, muito em função de algumas organizações apresentarem valores de receita altos em relação à maioria. Esses valores foram afetados, principalmente, por organizações como a Clinton Foundation, Viva Rio, Acted e Heifer International, que arrecadaram aproximadamente $60 \%$ das receitas no período analisado.

A Tabela 3 apresenta o percentual médio das receitas para cada ONG no período de 2015 a 2017. Além disso, apresenta-se a posição em que a ONG foi ordenada pela NGOAdvisor (2018) entre parênteses ao lado do nome da organização e o país em que a ONG possui sua sede principal registrada. 
Tabela 3 - Percentual médio das receitas (2015-2017)

\begin{tabular}{|c|c|c|c|c|c|c|c|c|}
\hline \multirow{2}{*}{ Nome } & \multirow{2}{*}{ País } & \multicolumn{4}{|c|}{ Receita Externa } & \multirow{2}{*}{$\begin{array}{l}\text { Receita } \\
\text { Própria }\end{array}$} & \multirow{2}{*}{$\begin{array}{c}\text { Investimento e } \\
\text { Juros }\end{array}$} & \multirow{2}{*}{ Outros } \\
\hline & & Doação & Subvenção & Híbrido & Total & & & \\
\hline One Acre Fund (14) & Quênia & 20,51 & 0 & 30,89 & 51,40 & 44,34 & 4,23 & 0,04 \\
\hline Rare (22) & EUA & 1,22 & 0 & 98,62 & 99,84 & 0 & 0,10 & 0,06 \\
\hline Greenpeace (24) & Holanda & 99,59 & 0 & 0 & 99,59 & 0 & 0 & 0,41 \\
\hline Heifer International (28) & EUA & 85,64 & 6,34 & 0 & 91,98 & 0,76 & 6,47 & 0,79 \\
\hline Acted (31) & França & 0,93 & 96,62 & 0 & 97,54 & 0,39 & 0,01 & 2,06 \\
\hline Ceres (34) & EUA & 10,68 & 67,63 & 0 & 78,31 & 20,29 & 0,20 & 1,19 \\
\hline Viva Rio (47) & Brasil & 0 & 99,91 & 0 & 99,91 & 0 & 0 & 0,09 \\
\hline Rainforest Alliance (57) & EUA & 15,10 & 36,12 & 4,12 & 55,35 & 43,71 & 0,32 & 0,62 \\
\hline $\begin{array}{l}\text { Global Footprint } \\
\text { Network (91) }\end{array}$ & EUA & 38,09 & 45,45 & 0 & 83,54 & 15,84 & 0,61 & 0,01 \\
\hline Waterkeeper (105) & EUA & 97,25 & 0 & 0 & 97,25 & 2,68 & 0 & 0,07 \\
\hline Breaking Ground (107) & EUA & 6,82 & 24,25 & 14,77 & 45,85 & 34,79 & 13,22 & 6,15 \\
\hline $\begin{array}{l}\text { Sitawi Finance for Good } \\
\qquad(119)\end{array}$ & Brasil & 51,24 & 30,62 & 0 & 81,87 & 14,00 & 4,14 & 0 \\
\hline Clinton Foundation (131) & EUA & 53,09 & 26,01 & 0 & 79,10 & 3,29 & 14,90 & 2,72 \\
\hline 350.Org (152) & EUA & 0,23 & 0 & 99,58 & 99,81 & 0 & 0,02 & 0,17 \\
\hline Global Witness (162) & Inglaterra & 53,34 & 45,82 & 0 & 99,16 & 0 & 0,16 & 0,68 \\
\hline The Ocean Cleanup (165) & Holanda & 99,34 & 0 & 0 & 99,34 & 0 & 0 & 0,66 \\
\hline $\begin{array}{c}\text { Green Cross } \\
\text { International (206) }\end{array}$ & Suíça & 49,81 & 46,81 & 0 & 96,61 & 0 & 3,26 & 0,14 \\
\hline Technoserve (207) & EUA & 2,30 & 24,22 & 71,87 & 98,39 & 0 & 0,98 & 0,63 \\
\hline Raven (247) & Canada & 57,67 & 37,14 & 0 & 94,81 & 4,83 & 0 & 0,36 \\
\hline $\begin{array}{c}\text { Development } \\
\text { Alternatives (249) }\end{array}$ & Índia & 0 & 97,32 & 0 & 97,32 & 0 & 0 & 2,68 \\
\hline Solar Cookers (275) & EUA & 77,22 & 18,69 & 0 & 95,90 & 3,29 & 0,37 & 0,43 \\
\hline $\begin{array}{c}\text { Climate Action Network } \\
\text { (277) }\end{array}$ & Líbano & 22,07 & 75,62 & 0 & 97,69 & 0 & 0 & 2,32 \\
\hline Fareshare (285) & Inglaterra & 89,83 & 0 & 0 & 89,83 & 10,12 & 0,05 & 0 \\
\hline Riverkeeper (289) & EUA & 91,12 & 0 & 0 & 91,12 & 7,16 & 0 & 1,72 \\
\hline $\begin{array}{c}\text { Susila Dharma } \\
\text { International (309) }\end{array}$ & Canadá & 76,48 & 18,99 & 0 & 95,48 & 0 & 4,52 & 0 \\
\hline Live \& Learn (318) & Austrália & 1,07 & 96,43 & 0 & 97,50 & 0 & 1,03 & 1,48 \\
\hline Vaga Lume (320) & Brasil & 68,80 & 18,16 & 0 & 86,96 & 11,18 & 1,86 & 0 \\
\hline $\begin{array}{l}\text { Institute for Sustainable } \\
\text { Communities (243) }\end{array}$ & EUA & 47,75 & 51,75 & 0 & 99,50 & 0,08 & 0,38 & 0,04 \\
\hline $\begin{array}{c}\text { Green Empowerment } \\
(376)\end{array}$ & EUA & 13,28 & 71,51 & 6,06 & 90,85 & 8,01 & 0,92 & 0,22 \\
\hline Food Tank (395) & EUA & 100 & 0 & 0 & 100 & 0 & 0 & 0 \\
\hline $\begin{array}{l}\text { Surfrider International } \\
\qquad(398)\end{array}$ & EUA & 25,78 & 0 & 65,05 & 90,82 & 8,80 & 0,38 & 0 \\
\hline Goonj (403) & Índia & 83,33 & 2,54 & 0 & 85,87 & 0 & 12,05 & 2,09 \\
\hline Benetech (416) & EUA & 16,84 & 0 & 0 & 16,84 & 82,78 & 0,38 & 0 \\
\hline Redress (495) & China & 44,87 & 53,88 & 0 & 98,74 & 0 & 0,05 & 1,21 \\
\hline
\end{tabular}

Fonte: Elaborado pelos autores

\subsubsection{Receita externa}

Em função da representatividade dessa categoria em relação ao total de recursos arrecadados nos três anos analisados e à possibilidade de distinguir algumas origens com aspectos específicos, foram criados três subgrupos nos quais foi possível separar as receitas auferidas por meio de Receita Externa, conforme já mencionado na seção 3.3, a saber: Doações, Subvenções e Híbrido. 


\subsubsection{Doações, Subvenções e Híbrido}

Todas as organizações da amostra final obtiveram, em ambos os anos, receitas classificadas como Doações, Subvenções ou Híbrido. Essa situação denota a importância dessas fontes de recursos, visto que 25 organizações em 2016 e 24 em 2015 apresentaram 90\% ou mais de receitas auferidas por tipos de receitas classificados como dessa categoria. A organização que apresentou menor participação dessa categoria foi a Benetech com 15\% em 2016 e 21\% em 2015.

A organização que arrecadou mais recursos, nos três anos analisados, no grupo doações, foi a Clinton Foundation, sendo que o valor arrecadado em 2016 representou 34\% do valor total arrecado por todas as organizações e 40\% nessa categoria em 2015. Essa organização também foi a que auferiu o maior valor de receita total em ambos os anos. A Clinton Foundation, nas notas explicativas, evidencia a origem de suas contribuições classificadas como doações, tendo como origem o governo, fundações e outros doadores.

No grupo subvenções, a organização Viva Rio foi a que mais arrecadou em 2016 e a Acted em 2015. As subvenções da Viva Rio são relacionadas com programas do governo federal, enquanto a Acted não divulgou a origem específica das suas subvenções.

Já no grupo Híbrido, a TechnoServe foi quem mais auferiu receitas em 2016 e 2015. Nesse sentido, seria importante para essa organização que fossem desmembrados os valores, de maneira que fosse possível observar se eles possuíam maior relação com subvenções ou doações, tendo em vista que a linha divulgada foi contribuições privadas e subvenções. Seria importante que esses valores fossem destacados em linhas diferentes por possuírem características distintas.

A organização Food Tank não apresentou um detalhamento pormenorizado de suas receitas, tendo em vista que apresentou apenas uma linha para evidenciar suas receitas. A organização não divulgou nota explicativa detalhando a receita divulgada como "Apoio direto do Público". A divulgação mais detalhada das receitas ou uma nota explicativa poderia auxiliar no entendimento de como essa receita foi auferida.

Os resultados encontrados para a receita externa neste estudo estão alinhados com aqueles de Good et al. (2015). As doações e subvenções foram as principais receitas, em média, para as ONGs em ambos os estudos. Cabe ressaltar que no presente estudo a amostra foi com organizações do setor ambiental para um período de três anos (2015 a 2017), enquanto no estudo de Good et al. (2015) a amostra foi composta pelas Top 100 ONGs (NGOAdvisor, 2018), e demonstrativos financeiros referentes ao ano de 2013.

\subsubsection{Receita Própria}

As receitas próprias podem ser auferidas por meio de prestação de serviços, consultorias, royalties, venda de mercadorias e licenciamentos, por exemplo.

A organização que auferiu a maior quantidade monetária, em ambos os anos, foi a One Acre Fund com \$ 37.973.407 no ano de 2016 e \$ 29.968.508 em 2015. Esses valores representam 34\% e 60\% do total arrecado pela categoria em 2016 e 2015, respectivamente. Essa organização se financia principalmente por meio da venda de produtos relacionados com a agricultura, a qual é sua principal atividade. A partir da análise percentual das receitas arrecadadas por uma organização em relação à sua receita total, a organização Benetech teve, em média, no período $80 \%$ de suas receitas classificadas como receita própria.

Além disso, somando as três organizações que mais arrecadaram nessa categoria, a saber Rainforest Alliance e Breaking Ground, além da supracitada Benetech, a participação na receita total é de 78\% em 2016. Nota-se, portanto, uma contribuição majoritária dessas três organizações para o montante total arrecadado por meio de Receita Própria.

Os resultados encontrados para a receita própria neste estudo estão alinhados com aqueles de c. A receita própria, em média, foi a terceira principal fonte de recursos para as ONGs em 
ambos os estudos. O percentual encontrado no presente estudo foi de aproximadamente $8 \%$ enquanto no estudo de Good et al. (2015) foi de $15 \%$.

\subsubsection{Investimento e Juros}

As receitas com Investimento e Juros podem ser obtidas por meio de juros auferidos, ganhos de capital e retornos de investimentos, sendo esses exemplos de tipos de receitas auferidos pelas organizações pertencentes à amostra final.

Da amostra, 62\%apresentou algum tipo de receita em pelo menos um dos anos analisados referentes a esta categoria. A organização que obteve maior representação percentual dessa categoria foi a GOONJ, obtendo 16\% das suas receitas totais, em 2016, por meio de receita com juros. Ela também apresentou a maior representatividade percentual em 2015, com 13\% de receitas com juros.

A organização que obteve o maior montante, em 2016, foi a Clinton Foundation com \$ 9.680.612. Esse valor foi divulgado como retorno sobre o investimento, sendo que nas notas explicativas é divulgado que nessa conta são incluídos os dividendos, juros e ganhos sobre as vendas de investimentos avaliados pelo valor justo. Nesse sentido, a organização divulga os valores referentes a cada um desses eventos nas notas explicativas, enquanto no Statement of Activities são evidenciados de forma agregada esses eventos. Já em 2015, a organização com maior valor arrecadado nesta categoria foi a One Acre Fund com \$ 4.639.376. Esse valor refere-se à venda de investimentos mantidos pela organização bem como ao ganho por colocar à disposição parte de seus ativos para outras organizações.

\subsubsection{Outros}

Foram caracterizadas receitas dessa natureza em 20 das 34 ONGs pertencentes à amostra, sendo que as nomenclaturas utilizadas foram semelhantes, a saber: Outras receitas, Outros e Diversos. Os valores pertencentes a esta categoria representaram $0,90 \%$ do total de receitas auferidas por todas as organizações.

O percentual máximo que essa categoria representou foi na organização Breaking Ground, nos anos de 2016 e 2015, com percentuais de 7,67\% e 4,87\%, respectivamente. Com o aumento no nível de transparência das organizações, a tendência seria de uma redução nos valores encontrados para essa categoria, visto que, com o aumento da representatividade, a tendência é que esse valor seja melhor evidenciado.

A representatividade dos valores de investimentos e juros no presente estudo foi superior, em média, na comparação com os valores classificados como Outros. Esse resultado não está alinhado com o encontrado por Good et al. (2015). No presente estudo, o valor classificado como outros foi inferior a $1 \%$, enquanto no estudo mencionado foi de aproximadamente 3,5\%. Esse resultado pode demonstrar que as organizações estejam mais transparentes e que com diminuta divulgação não se identifica uma fonte específica de recursos.

\subsection{Diversificação de Receitas}

A Tabela 4 apresenta o índice HHI, a fim de identificar o nível de diversificação de receitas ao longo dos anos analisados bem como sua média para cada organização. Quanto mais próximo de 1, mais diversificadas são as receitas, enquanto o indicador igual a 0 representa que somente existe uma fonte de receita na organização. 
Tabela 4 - Diversificação de receitas e estatísticas descritivas

\begin{tabular}{|c|c|c|c|c|}
\hline ONG & 2017 & 2016 & 2015 & Média \\
\hline One Acre Fund & 0,4957 & 0,5848 & 0,5877 & 0,5561 \\
\hline Rare & 0,0207 & 0,0117 & 0,0490 & 0,0271 \\
\hline Greenpeace & 0,0136 & 0,0070 & 0,0038 & 0,0081 \\
\hline Heifer International & 0,4591 & 0,1019 & 0,1510 & 0,2373 \\
\hline Acted & 0,1653 & 0,0119 & 0,0131 & 0,0635 \\
\hline Ceres & 0,4234 & 0,4695 & 0,5227 & 0,4719 \\
\hline Viva Rio & 0,0046 & 0,0006 & 0,0004 & 0,0019 \\
\hline Rainforest Alliance & 0,6818 & 0,6209 & 0,6306 & 0,6444 \\
\hline Global Footprint Network & 0,2620 & 0,5388 & 0,4218 & 0,4075 \\
\hline Waterkeeper & 0,1348 & 0,0072 & 0,0125 & 0,0515 \\
\hline Breaking Ground & 0,6375 & 0,6215 & 0,6053 & 0,6214 \\
\hline Sitawi Finance For Good & 0,1494 & 0,3393 & 0,4114 & 0,3000 \\
\hline Clinton Foundation & 0,6642 & 0,5408 & 0,4916 & 0,5655 \\
\hline 350.Org & 0,0047 & 0,0066 & 0,0139 & 0,0084 \\
\hline Global Witness & 0,5060 & 0,4929 & 0,5094 & 0,5027 \\
\hline The Ocean Cleanup & 0,0388 & 0,0000 & 0,0000 & 0,0129 \\
\hline Green Cross International & ND & 0,5326 & 0,5310 & 0,5318 \\
\hline Technoserve & 0,4181 & 0,4436 & 0,4094 & 0,4237 \\
\hline Raven & 0,5011 & 0,5606 & 0,3821 & 0,4813 \\
\hline Development Alternative & 0,0183 & 0,0590 & 0,0785 & 0,0519 \\
\hline Solar Cookers & 0,3985 & 0,2896 & 0,4013 & 0,3632 \\
\hline Climate Action Network & ND & 0,5257 & 0,1089 & 0,3173 \\
\hline Fareshare & 0,0402 & 0,3699 & 0,0762 & 0,1621 \\
\hline Riverkeeper & 0,3669 & 0,0346 & 0,0292 & 0,1435 \\
\hline Susila Dharma International Association & 0,2378 & 0,4729 & 0,3680 & 0,3596 \\
\hline Live \& Learn & 0,0761 & 0,0684 & 0,0647 & 0,0697 \\
\hline Vaga Lume & 0,4039 & 0,4542 & 0,5677 & 0,4753 \\
\hline Institute For Sustainable Communities & 0,5042 & 0,4497 & 0,4351 & 0,4630 \\
\hline Green Empowerment & 0,4529 & 0,4558 & 0,4239 & 0,4442 \\
\hline Food Tank & 0,0000 & 0,0000 & 0,0000 & 0,0000 \\
\hline Surfrider International & 0,4086 & 0,5544 & 0,5220 & 0,4950 \\
\hline Goonj & 0,1760 & 0,3301 & 0,3504 & 0,2855 \\
\hline Benetech & 0,2473 & 0,2675 & 0,3389 & 0,2846 \\
\hline Redress & 0,4708 & 0,4555 & 0,4463 & 0,4575 \\
\hline \multicolumn{5}{|c|}{ Estatísticas Descritivas } \\
\hline & 2017 & 2016 & 2015 & Média \\
\hline Média & 0,2932 & 0,3141 & 0,2929 & 0,3026 \\
\hline Máximo & 0,6818 & 0,6215 & 0,6306 & 0,6444 \\
\hline Mediana & 0,3145 & 0,4068 & 0,3750 & 0,3384 \\
\hline Mínimo & 0,0000 & 0,0000 & 0,0000 & 0,0000 \\
\hline Desvio Padrão & 0,2184 & 0,2315 & 0,2244 & 0,2115 \\
\hline $1^{\mathrm{o}}$ Quartil & 0,0491 & 0,0289 & 0,0441 & 0,0606 \\
\hline $3^{\circ}$ Quartil & 0,4679 & 0,5274 & 0,4960 & 0,4768 \\
\hline
\end{tabular}

Notas: As ONGs Green Cross International e Climate Action Network não apresentaram a demonstração que evidencia as receitas referente ao ano de 2017. Portanto, não foi possível calcular o indicador para estas ONGs no ano de 2017. Fonte: Elaborada pelos autores

A ONG Rainforest Alliance apresentou o maior indicador de diversificação com média de 0,6444. Por outro lado, a ONG Food Tank apresentou o indicador HHI igual a 0 para todos os anos analisados, o que indica que ela somente possui uma fonte de receita, a saber, Doações.

Referente as estatísticas descritivas, é possível perceber que, em média, as ONGs da amostra apresentaram um nível de 0,3026 de diversificação de receitas. Nesse sentido, este nível foi mantido para os 3 anos analisados, tendo que a vista que a média oscilou em nível próximo a 
0,3000. Este resultado está alinhado com aqueles encontrados por Carroll e Stater (2009) e acima da média de diversificação de receitas indicada no estudo de Shea e Wang (2016).

Ressalta-se que $25 \%$ das ONGs apresentaram indicador médio inferior a 0,1 e $75 \%$ destas indicador inferior médio a 0,50. Este resultado demonstra que apenas $25 \%$ das ONGs apresentaram indicadores médios mais próximos de 1 do que 0 . Ainda, o valor máximo, em média, foi 0,6444 .

\section{CONCLUSÃO}

O objetivo do presente artigo foi identificar o nível de diversificação de receitas das maiores ONGs ambientais do mundo. Os resultados indicam que as ONGs analisadas não apresentaram receitas diversificadas, tendo em vista que a maioria destas não apresentou indicador HHI superior a 0,50 . Os resultados encontrados na pesquisa estão alinhados com aqueles sugeridos por Carroll e Stater (2009), e acima daqueles indicados por Shea e Wang (2016).

Ademais, as organizações pertencentes à amostra foram dependentes das receitas externas, oscilando em aproximadamente $90 \%$ no período analisado. Há organizações como One Acre Fund, Rainforest Alliance e Breaking Ground, no entanto, que apresentam maior parcela de receita própria do que a média na composição de suas receitas. Além disso, todas as organizações da amostra final obtiveram, em ambos os anos, receitas classificadas como Doações, Subvenções ou Híbrido, sendo estes os grupos elaborados para a receita externa.

A concentração de receitas externas faz com que as organizações da amostra fiquem suscetíveis à redução do fluxo de recursos por questões não relacionadas a elas. Uma crise nas contas públicas de determinado país, por exemplo, pode reduzir o valor repassado por meio de subvenções. As doações podem ser reduzidas por uma necessidade de as famílias reduzirem seus gastos, em virtude de uma crise econômica. Por outro lado, a busca por outras formas de receitas fará com que o custo administrativo aumente, tendo como reflexo (ceteris paribus) menos recursos para se investir na atividade principal da organização (Saxton et al., 2014).

Notou-se também que existe a necessidade de algumas adaptações nos demonstrativos analisados (Statement of Activities ou equivalente), visando tornar a divulgação das organizações mais transparente. Algumas organizações, por exemplo, divulgaram apenas uma ou duas linhas no demonstrativo, sendo de característica muito geral e sem explicar mais sobre o evento nas notas explicativas. Percebe-se, então, a necessidade de classificação mais adequada das receitas, de forma que as contas sejam dispostas de maneira mais analítica possível para que recursos de origem distinta não sejam agregados de modo que não se saiba efetivamente a origem da receita. Além disso, das 56 ONGs do setor ambiental que participam do ranking analisado, 22 delas não divulgaram as informações necessárias para participarem do presente estudo.

Por um lado, a dificuldade de se compreender clara e objetivamente como as ONGs são financiadas parece ser um problema que precisa ser resolvido com urgência, pois tais organizações são quase que totalmente dependentes de recursos externos. Por outro, a facilidade de se compreender a origem dos recursos auferidos pelas principais ONGs do setor ambiental poderia impulsionar a arrecadação das organizações, visto que demonstrariam transparência e accountability.

A composição das receitas das ONGs que compuseram a amostra do presente estudo, em média, está alinhada com os resultados encontrados por Good et al. (2015), principalmente na ordem de representatividade das receitas. As diferenças encontradas foram no nível dessa representatividade, sendo que no resultado deste estudo as ONGs possuem mais dependência de receitas advindas de doações e subvenções do que no estudo supracitado. Além disso, a receita própria auferida pelas ONGs do presente estudo é inferior, em média, na comparação com os resultados encontrados por Good et al. (2015). 
Os resultados encontrados no presente estudo não podem ser generalizados para organizações de outros setores, visto que a amostragem foi não probabilística, selecionando apenas ONGs do setor ambiental do ranking elaborado pela NGOAdvisor (2018).

Recomenda-se, para futuras pesquisas, analisar não somente o setor ambiental, mas também outros setores, possibilitando análise comparativa entre eles. Com isso, poder-se-ia avaliar as características específicas de cada setor. Outra possibilidade é aumentar o período analisado, tendo em vista analisar possíveis alterações nas características das fontes de recursos das organizações em períodos com crises ou após fatos positivos ou negativos associados a organização, por exemplo.

Ainda, a partir da análise dos relatórios anuais das ONGs, percebeu-se que algumas divulgaram a lista com o nome dos maiores doadores no período do relatório. Essa é uma forma interessante de ser transparente e ao mesmo tempo divulgar organizações, empresas, universidades, entre outros, que estão colaborando para que as ONGs consigam desenvolver seu trabalho. Essas informações podem ser analisadas para identificar quais os grupos da sociedade (empresas, universidades, pessoas físicas) que subsidiam as ONGs e analisar quais destes são mais relevantes para financiar suas atividades.

\section{REFERÊNCIAS}

Arya, A., \& Mittendorf, B. (2016). Donor Reliance on Accounting and its Consequences for the Charitable Distribution Channel. Production and Operations Management, 25(8), 1319-1331. https://doi.org/10.1111/poms.12550

Aschari-Lincoln, J., \& Jäger, U. P. (2015). Analysis of Determinants of Revenue Sources for International NGOs: Influence of Beneficiaries and Organizational Characteristics. Nonprofit and Voluntary Sector Quarterly, 45(3), 612-629. https://doi.org/10.1177/0899764015595721

Becker, A. (2018). An Experimental Study of Voluntary Nonprofit Accountability and Effects on Public Trust, Reputation, Perceived Quality, and Donation Behavior. Nonprofit and Voluntary Sector Quarterly, 47(3), 562-582. https://doi.org/10.1177/0899764018756200

Bonsón-Ponte, E., Escobar-Rodríguez, T., \& Flores-Muñoz, F. (2006). Online transparency of the banking sector. Online Information Review, 30(6), 714-730.

https://doi.org/10.1108/14684520610716180

Burks, J. J. (2015). Accounting errors in nonprofit organizations. Accounting Horizons, 29(2), 341361. https://doi.org/10.2308/acch-51017

Carroll, D. A., \& Stater, K. J. (2009). Revenue Diversification in Nonprofit Organizations: Does it Lead to Financial Stability? Journal of Public Administration Research and Theory, 19(4), 947-966. https://doi.org/10.1093/jopart/mun025

Chikoto, G. L., \& Neely, D. G. (2014). Building Nonprofit Financial Capacity: The Impact of Revenue Concentration and Overhead Costs. Nonprofit and Voluntary Sector Quarterly, 43(3), 570-588. https://doi.org/10.1177/0899764012474120

Conway, S. L., O'Keefe, P. A., \& Hrasky, S. L. (2015). Legitimacy, accountability and impression management in NGOs: the Indian Ocean tsunami. Accounting, Auditing \& Accountability Journal, 28(7), 1075-1098. https://doi.org/10.1108/AAAJ-04-2012-01007

FASB. (1993). FAS 117. Connecticut. Recuperado de 
http://www.fasb.org/jsp/FASB/Document_C/DocumentPage?cid=1218220124031\&acceptedDis claimer=true

Foundation, C. A. (2017). Charities Aid Foundation. Recuperado de https://www.cafonline.org/about-us/publications/2017-publications/caf-world-giving-index2017

Gálvez Rodríguez, M. del M., Caba Pérez, M. del C., \& López Godoy, M. (2012). Determining Factors in Online Transparency of NGOs: A Spanish Case Study. VOLUNTAS: International Journal of Voluntary and Nonprofit Organizations, 23(3), 661-683. https://doi.org/10.1007/s11266011-9229-x

Good, Kevin Joseph;, Borba, J. A., \& Maragno, L. M. . (2015). Supporting Stakeholder Relationship Management via Disclosure on Resource Origins: Evidence from the World's Top NGOs. Sociedade, Contabilidade e Gestão, Rio de Janeiro, 10(2), 139-156.

Good, Kevin Joseph; Maragno, L. M. D., \& Borba, J. A. (2016). Online Financial Disclosure as an Accountability Mechanism for NGOs Across the Globe. SSRN Electronic Journal. https://doi.org/10.2139/ssrn.2802328

Good, Kevin Joseph, Maragno, L. M. D., \& Borba, J. A. (2018). ONLINE FINANCIAL DISCLOSURE AS AN ACCOUNTABILITY MECHANISM: EVIDENCE FROM THE WORLD' S TOP 100 NGOS. Revista Universo Contábil, 14(1), 161-180.

Gordon, T. P. (2013). Not-for-profit accounting in a changing world of standard setting: What professors and students need to know. Journal of Accounting Education, 31(3), 232-243. https://doi.org/10.1016/j.jaccedu.2013.06.005

Harris, E., Petrovits, C., \& Yetman, M. H. (2017). Why Bad Things Happen to Good Organizations: The Link Between Governance and Asset Diversions in Public Charities. Journal of Business Ethics, 146(1), 149-166. https://doi.org/10.1007/s10551-015-2921-9

Hyndman, N., \& McConville, D. (2016). Transparency in Reporting on Charities' Efficiency. Nonprofit and Voluntary Sector Quarterly, 45(4), 844-865. https://doi.org/10.1177/0899764015603205

Journal, T. G. (2018). The Global Journal. Recuperado de http://www.theglobaljournal.net/

Keating, E. K., \& Frumkin, P. (2003). Reengineering Nonprofit Financial Accountability: Toward a More Reliable Foundation for Regulation. Public Administration Review, 63(1), 3-15. https://doi.org/10.1111/1540-6210.00260

Mahmood, Z., Ahmad, Z., Ali, W., \& Ejaz, A. (2017). Does Environmental Disclosure Relate to Environmental Performance? Reconciling Legitimacy Theory and Voluntary Disclosure Theory. Pakistan Journal of Commerce and Social Sciences (PJCSS), 11(3), 1134-1152.

Markowitz, H. (1952). Portfolio selection. The Journal of Finance, 7(1), 77-91.

Mayer, W. J., Wang, H. chen, Egginton, J. F., \& Flint, H. S. (2014). The Impact of Revenue Diversification on Expected Revenue and Volatility for Nonprofit Organizations. Nonprofit 
and Voluntary Sector Quarterly, 43(2), 374-392. https://doi.org/10.1177/0899764012464696

NGOAdvisor. (2018). NGOAdvisor. Recuperado from https://www.ngoadvisor.net/

Pacheco, R. R., Macagnan, C. B., \& Seibert, R. M. (2016). Fatores Explicativos do Nível de Evidenciação de Informações de Organizações do Terceiro Setor. Revista de Gestão, Finanças e Contabilidade, 6(2), 72-93. https://doi.org/10.18028/2238-5320/rgfc.v6n2p72-93

Parsons, L. M. (2007). The Impact of Financial Information and Voluntary Disclosures on Contributions to Not-For-Profit Organizations. Behavioral Research in Accounting, 19(1), 179_ 196. https://doi.org/10.2308/bria.2007.19.1.179

Parsons, L. M., Pryor, C., \& Roberts, A. A. (2017). Pressure to Manage Ratios and Willingness to Do So: Evidence From Nonprofit Managers. Nonprofit and Voluntary Sector Quarterly, 46(4), 705724. https://doi.org/10.1177/0899764017692037

Pereira, R. S., Moraes, F. C. C., Mattos Júnior, A. B., \& Palmisano, A. (2013). Especificidades da Gestão no Terceiro Setor. Revista Organizações Em Contexto, 9(18), 167-195. https://doi.org/10.15603/1982-8756/roc.v9n18p167-195

Prakash, A., \& Gugerty, M. K. (2010). Trust but verify? Voluntary regulation programs in the nonprofit sector. Regulation \& Governance, 4(1), 22-47. https://doi.org/10.1111/j.17485991.2009.01067.x

Reheul, A.-M., Van Caneghem, T., Van den Bogaerd, M., \& Verbruggen, S. (2017). Auditor gender, experience and reporting in nonprofit organizations. Managerial Auditing Journal, 32(6), 550577. https://doi.org/10.1108/MAJ-01-2016-1296

Saxton, G. D., \& Guo, C. (2011). Accountability online: Understanding the web-based accountability practices of nonprofit organizations. Nonprofit and Voluntary Sector Quarterly, 40(2), 270-295. https://doi.org/10.1177/0899764009341086

Saxton, G. D., Neely, D. G., \& Guo, C. (2014). Web disclosure and the market for charitable contributions. Journal of Accounting and Public Policy, 33(2), 127-144. https://doi.org/10.1016/j.jaccpubpol.2013.12.003

Shea, J., \& Wang, J. Q. (2016). Revenue Diversification in Housing Nonprofits. Nonprofit and Voluntary Sector Quarterly, 45(3), 548-567. https://doi.org/10.1177/0899764015593643

Stafford, E. R., Polonsky, M. J., \& Hartman, C. L. (2000). Business Collaboration and Strategic Bridging : a Case Analysis of the Alliance. Business Strategy and the Environment, 135, 122-135.

Tate, S. L. (2007). Auditor change and auditor choice in nonprofit organizations. Auditing, 26(1), 47-70. https://doi.org/10.2308/aud.2007.26.1.47

Tristão, Vi. T. V., \& Tristão, J. A. M. (2016). A Contribuição das ONGs para a Educação Ambiental: Uma Avaliação da Percepção dos Stakeholders. Ambiente \& Sociedade, 19(3), 47-66. https://doi.org/10.1590/1809-4422ASOC132656V1932016

Verbruggen, S., Christiaens, J., \& Milis, K. (2011). Can Resource Dependence and Coercive Isomorphism Explain Nonprofit Organizations' Compliance With Reporting Standards? 
Nonprofit and Voluntary Sector Quarterly, 40(1), 5-32. https://doi.org/10.1177/0899764009355061

Vermeer, T. E., Edmonds, C. T., \& Asthana, S. C. (2014). Organizational Form and Accounting Choice: Are Nonprofit or For-Profit Managers More Aggressive? The Accounting Review, 89(5), 1867-1893. https://doi.org/10.2308/accr-50796

von Schnurbein, G., \& Fritz, T. M. (2017). Benefits and Drivers of Nonprofit Revenue Concentration. Nonprofit and Voluntary Sector Quarterly, 46(5), 922-943. https://doi.org/10.1177/0899764017713876

Wassmer, U., Paquin, R., \& Sharma, S. (2014). The Engagement of Firms in Environmental Collaborations. Business \& Society, 53(6), 754-786. https://doi.org/10.1177/0007650312439865

Wilsker, A. L., \& Young, D. R. (2010). How Does Program Composition Affect the Revenues of Nonprofit Organizations?: Investigating a Benefits Theory of Nonprofit Finance. Public Finance Review, 38(2), 193-216. https://doi.org/10.1177/1091142110369238 